\title{
La búsqueda de la identidad nacional de Irlanda a través de la arquitectura eclesial
}

The search for the Irish national identity through church architecture

Eugenio José Rodríguez González

https://doi.org/10.17979/aarc.2011.2.2.5055

\section{EL CONTEXTO HISTÓRICO}

Irlanda comienza el siglo XX en plena efervescencia nacionalista. En 1893 se había fundado la Liga Gaélica, de la que el poeta William Butler Yeats fue uno de sus inspiradores. Por otro lado, el partido republicano Sinn Féinn (Nosotros Mismos), reagrupado tras Arthur Griffith, exige la formación inmediata de un Parlamento nacional irlandés. La situación se hace insostenible y estalla el lunes de Pascua de 1916, cuando los militantes de la Irish Republican Brotherhood toman la oficina central de correos de Dublín y establecen un gobierno provisional. La sublevación fracasa y sus dirigentes son ejecutados por los británicos, excepto Eamon de Valera, que se coloca al frente del Sinn Féinn. Se multiplican los atentados nacionalistas y, en 1921, tras una dura represión británica, el Tratado Angloirlandés reconoce la independencia de la parte sur de la isla (el Eire, mayoritariamente católico), quedando la parte norte (el Ulster, predominantemente protestante) en manos británicas. Comienza una guerra civil entre los partidarios y los detractores del Tratado, de la que el país sale en 1923 exangüe y, por mucho tiempo, traumatizado.

Irlanda emprende entonces, y durante un tiempo, un camino de búsqueda introspectiva de su identidad cultural, lo que no es sino un espejo de tendencias observadas por doquier en muchas culturas post-coloniales. Seguiremos ese proceso de búsqueda a través de la arquitectura de raíz católica, ya que, al igual que en otros países europeos sometidos a dominio extranjero, cual sería por ejemplo el caso de Polonia, la religión constituyó también para Irlanda una de las más firmes referencias para el establecimiento de su identidad nacional.

\section{LAS PRIMERAS DECADAS DEL SIGLO XX: EL ESTILO HIBERNO-ROMÁNICO}

Comenzamos, por tanto, nuestro recorrido arquitectónico en los albores del siglo XX. El neogótico, estilo dominante en la arquitectura eclesial irlandesa durante la mayor parte del siglo XIX, hace sentir su presencia durante en los primeros momentos de la nueva centuria, aunque ya las formas del románico van ganando popularidad. Sirvan como ejemplos paradigmáticos la neogótica catedral católica de Letterkenny (William Hague y Thomas McNamara, 1890-1901) (Fig. 1) y la catedral episcopaliana de Santa Ana en Belfast, proyectada por Sir Thomas Drew en románico normando, manifestando ambas las tendencias predominantes de las respectivas confesiones en el cambio de siglo. Por el contrario, la influencia del Art Nouveau, al revés que en el resto de Europa, fue leve en la arquitectura eclesial irlandesa, y se limitó a las iglesias de las confesiones protestantes del Ulster1.

La reacción contra el recargado neogótico de inspiración inglesa o normanda (símbolo, además, del reprobado dominio inglés) fue inevitable, y se muestra en la 


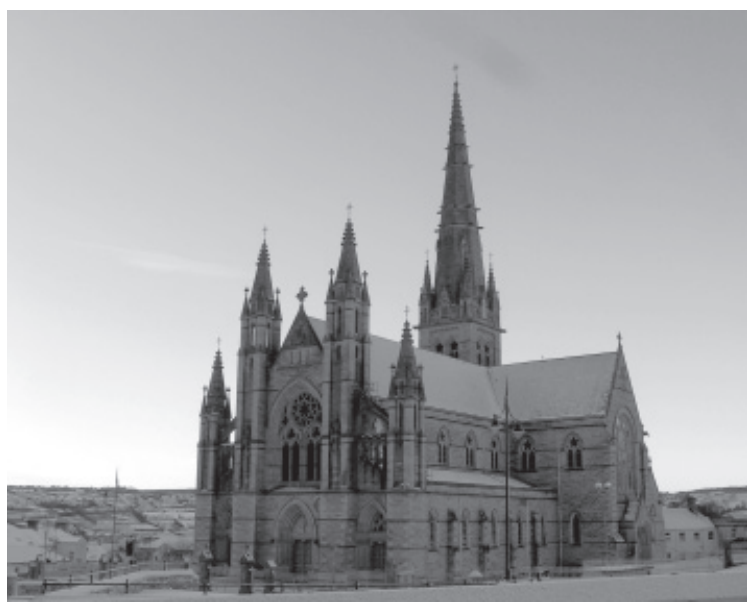

Fig. 1. William Hague y Thomas McNamara, Catedral católica, Letterkenny (1890/1901)

tendencia llamada hiberno-románico, intento de un genuino estilo irlandés para la arquitectura eclesial, retomando las formas inequívocamente autóctonas de los primeros tiempos del cristianismo en la isla junto con las del románico, tendencia ésta que se había estado desarrollando durante décadas y que, en lo referente a las artes visuales, buscó la recreación de las glorias del pasado celta ${ }^{2}$.

Uno de los ejemplos más afortunados lo constituyó la iglesia de St. Enda en Spiddal (Fig. 2), diseñada por William Anthony Scott. De una ruda sencillez y audacia de formas, recordaba el carácter de las primeras iglesias cristianas de Irlanda, aunque no fuese arqueológicamente rigurosa. La crítica nacionalista se refería a ella como «la primera muestra de lo que esperamos sea una fresca y vigorosa oleada arquitectónica en Irlanda (...) Es un desarrollo del antiguo románico irlandés para propósitos arquitectónicos actuales. En este sentido se puede decir que comienza una moderna arquitectura vernácula en Irlanda» ${ }^{3}$. Scott es el miembro más destacado de la nueva escuela de jóvenes arquitectos irlandeses que emerge en las primeras décadas del nuevo siglo. De corta carrera, aún diseñó otra obra significativa: la gran iglesia de peregrinación de San Patricio (Fig. 3), ubicada en una de las islas del lago Dergh, Station Island, proyectada en 1919, y construida póstumamente entre 1926 y 1931. De planta octogonal, con cierto aire irlandés debido a sus

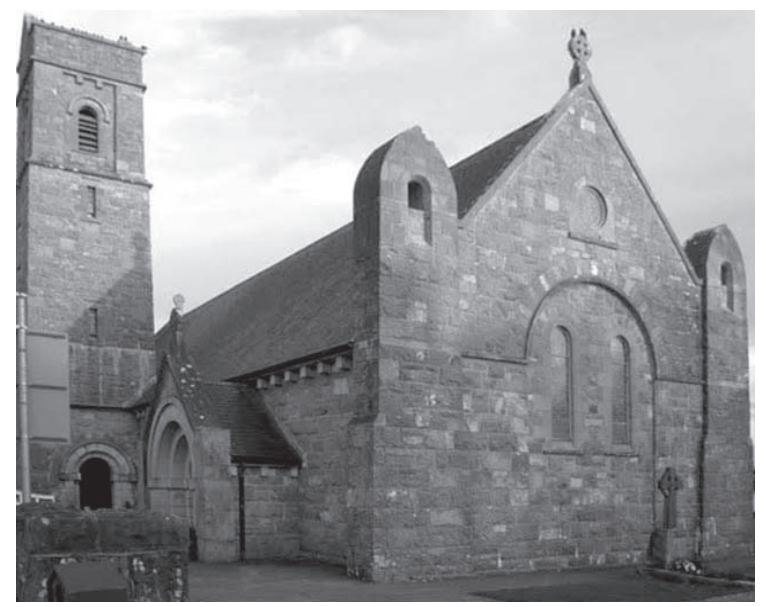

Fig. 2. William Anthony Scott, St. Enda, Spiddal (1912 ca.)

pequeñas torres de planta circular (como las de los primeros monasterios cristianos irlandeses) y a los motivos ornamentales de entrelazados celtas, se ha considerado la iglesia más importante de este periodo en Irlanda.

La tendencia del hiberno-románico fue continuada por otros arquitectos, ya con rasgos claramente faltos de originalidad. Como un caso especial cabría mencionar la capilla del Honan Hostel de Cork (James McMullen, 1915/16), que aludía a numerosos y reverenciados precedentes del románico irlandés (Fig. 4). Aunque la arquitectura de Honan Chapel resulta un tanto decepcionante, su principal mérito descansa en su mobiliario, que representa una buena parte del mejor trabajo irlandés de artes y oficios de la época, ya sea por la excelente forja de estilo celta diseñada por William Anthony Scott, ya por las brillantes vidrieras de Harry Clarke y del estudio Tower of Glass, ambos de Dublín. La incorporación de la artesanía irlandesa a las iglesias contemporáneas ya se había comenzado en la catedral de Loughrea bajo la dirección de Scott en 1903, pero su alcance completo se manifestó aquí más claramente que en ningún otro lugar.

Al hablar de estilo hiberno-románico no hay que olvidar la gran iglesia de St. Patrick en Newport (1915/18) (Fig. 5), proyectada por Rudolf Butler. Muestra los primeros rasgos claramente irlandeses, como las paredes en pendiente, un hastial tangente y 


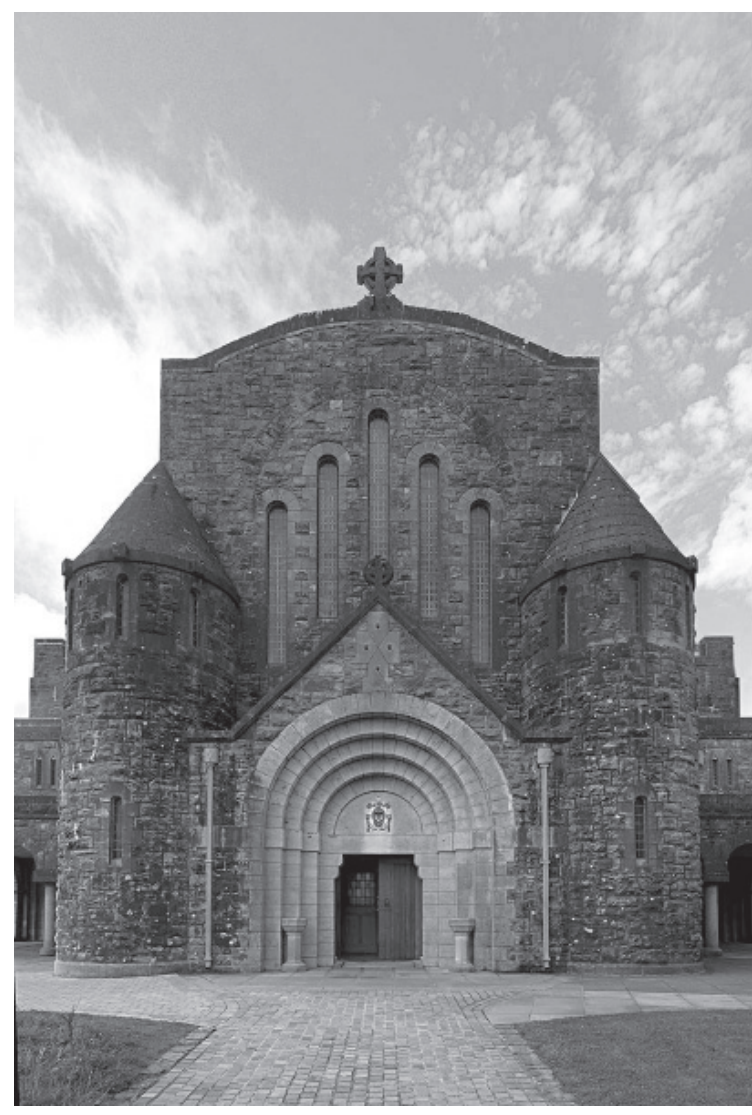

Fig. 3. William Anthony Scott, San Patricio, Station Island (1919-1926/31)

Fig. 5. Rudolf Butler, St. Patrick, Newport (1915/18)

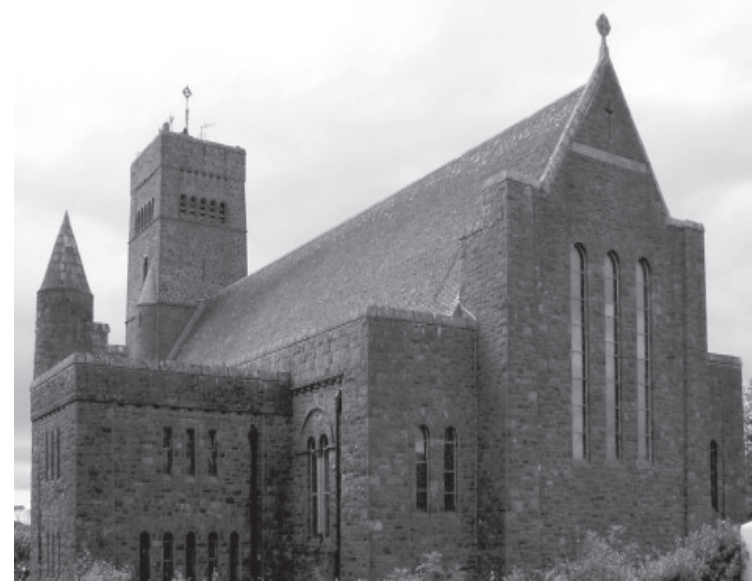

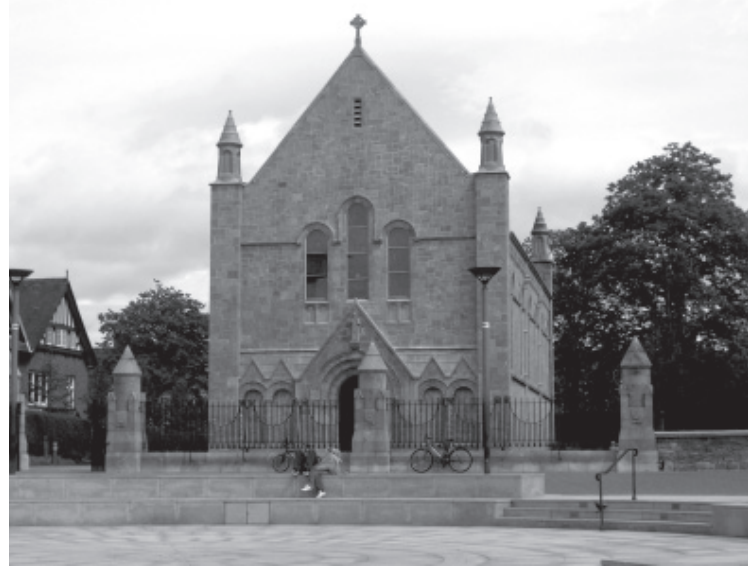

Fig. 4. James McMullen, Capilla del Honan Hostel, Cork (1915/16)

Fig. 6. Barry Byrne, Cristo Rey, Cork (1929/31)

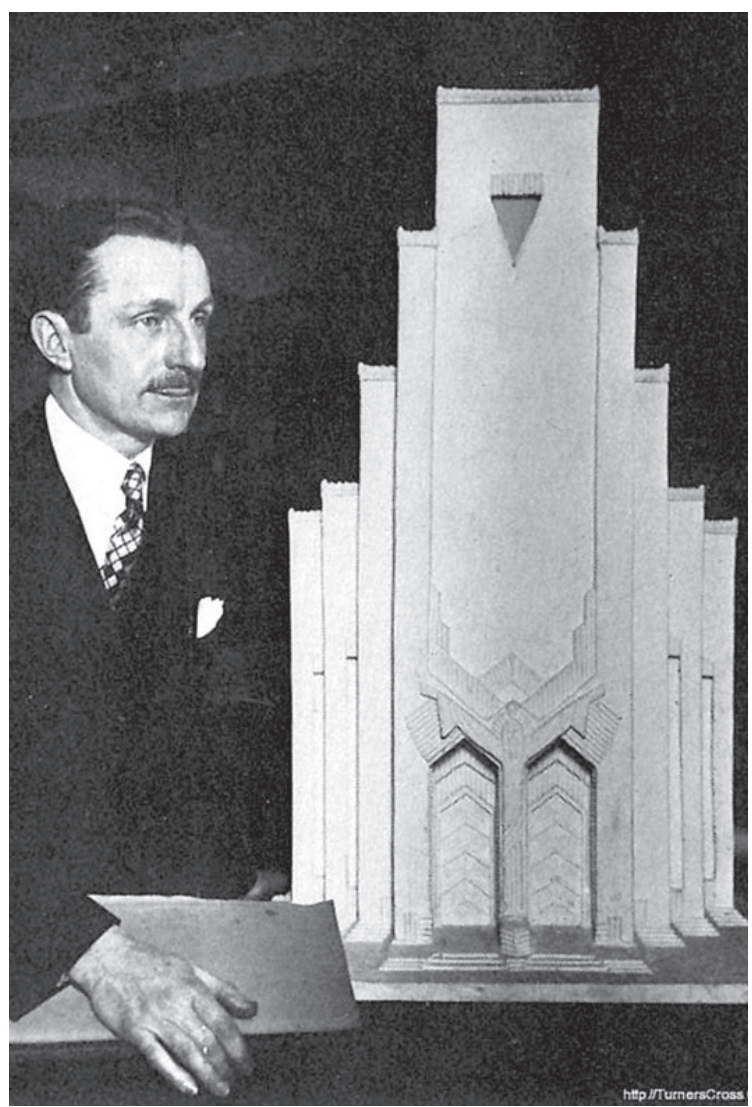




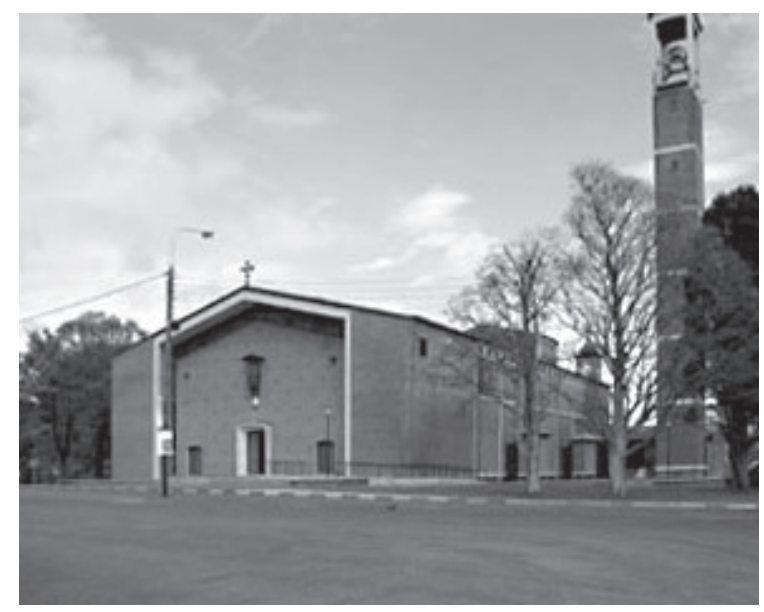

Fig. 7. Gerald McNicholl, Garrison Church of St. Brigid, Curragh Military Camp (1955/60)

jambas descendentes hacia el vano oeste, incorporando también el motivo irlandés de la torre de planta circular. Butler siguió utilizando el hiberno-románico a lo largo de los años veinte en iglesias como las de Belclere (1920/25), Scotthouse (1924) y Killany (1925/31).

El hiberno-románico como intento de estilo nacional, junto con el románico lombardo, el neoclasicismo o el neogótico, conforman la moda historicista de los años de entreguerras, para desesperación de la generación de arquitectos más jóvenes, entusiasmados con la arquitectura del Movimiento Moderno y ansiosos por propagarla en la isla.

\section{UN HITO AISLADO: LA IGLESIA DE CRISTO REY}

Dentro de este estado de cosas constituye una excepción, o más bien un adelanto de tendencia, la construcción de la primera iglesia abiertamente moderna de Irlanda: la iglesia católica de Cristo Rey, proyectada por el arquitecto de Chicago Barry Byrne (Fig. 6). Construida en Cork entre 1929 y 1931, esta iglesia fue reconocida entonces como la mayor ruptura con la arquitectura religiosa convencional jamás llevada a cabo en este país ${ }^{4}$. En el contexto irlandés, fue revolucionaria por su planta, su técnica constructiva y su lenguaje moderno, y tal vez por ello fue acogida con frialdad por la jerarquía eclesiástica -incluido el cardenal Dr. Daniel Cohalan, que había sido su principal impulsor- así como por la crítica arquitectónica especializada, y no tuvo por ello

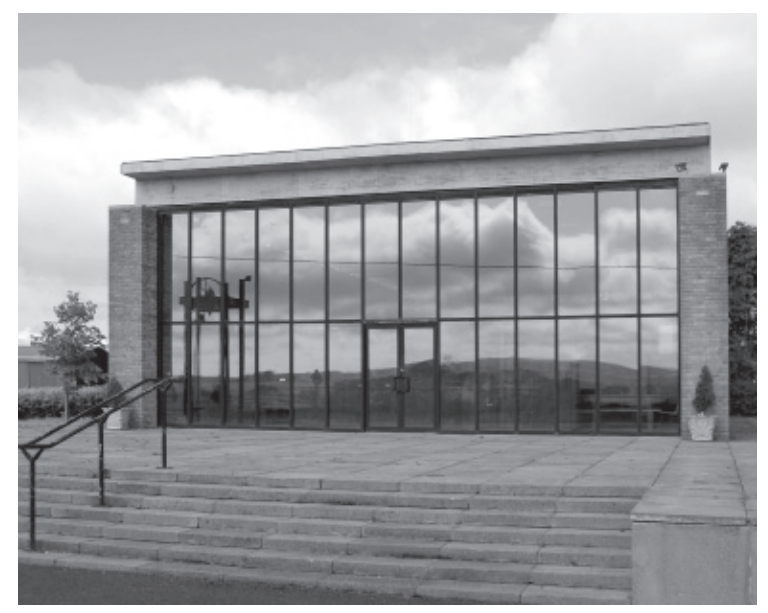

Fig. 8. Ronald Tallon, Corpus Christi, Knockanure (1964)

ninguna influencia sobre la arquitectura eclesial irlandesa (los estilos tradicionales iban a prevalecer sin excepción durante las dos siguientes décadas o incluso más). Solo la acompañan en su modernidad dos pequeñas capillas realizadas por Joseph Downes: Nuestra Señora de Lourdes, en Drogheda (1935, ya demolida) y la capilla del hospital de Kilkenny (1936). Diseñadas en el sencillo lenguaje de la cubierta plana, ambas se pueden considerar como reminiscencias de la influencia de las iglesias modernas alemanas del periodo de entreguerras.

Los años cuarenta son, en Irlanda, años de pobreza en lo material y de ensimismamiento en lo que se refiere al espíritu nacional. Pero ya camino de los años cincuenta, la moderna arquitectura eclesial se pone en marcha, si bien lentamente, con obras de aspecto moderno, que siguen teniendo que vencer cierta tendencia social hacia los diseños de estilo y planta tradicionales (neobizantino, neorrománico, etc.), hasta llegar a la elegante Garrison Church of St. Brigid en el Curragh Military Camp (1955/60) (Fig. 7), realizada para la Oficina de Obras Públicas por Gerald McNicholl, y que es un buen ejemplo de contenido diseño moderno que encuentra la más amplia aceptación en los años cincuenta.

\section{LOS NUEVOS AIRES DE LOS SESENTA}

Según nos vamos acercando a los años sesenta podemos observar ciertos cambios. En 1959, Sean Lemass sustituye a Eamon de Valera como Primer Ministro. 


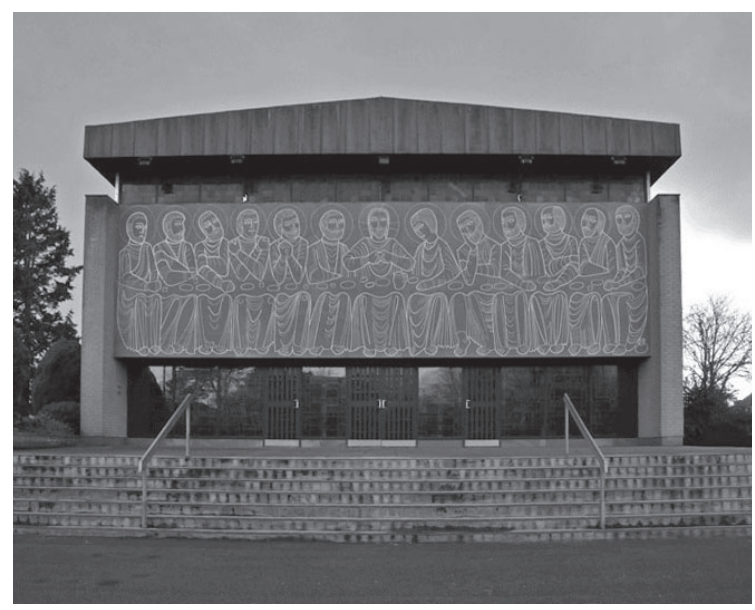

Fig. 9. Patrick Haughey, Santa Teresa, Sion Mills, (1963/65)

Lemass lanza el Programme for Economic Expansion, que logra relanzar la economía irlandesa. Irlanda se abre al exterior con la firma del Tratado Anglo-irlandés de Comercio (1965) e inicia las negociaciones para su adhesión al Mercado Común. El crecimiento vegetativo de la población y la disminución de la emigración estimulan la expansión de las ciudades hacia los suburbios, lo que impulsa la construcción de nuevos lugares de culto. Pese a su generalizado conservadurismo, la Iglesia Católica había estado abierta a limitados cambios en el arte litúrgico y en la arquitectura religiosa, y llega a ser un factor clave en el mecenazgo de una nueva estética a lo largo de los años sesenta, sobre todo tras el decisivo Concilio Vaticano II. El cambio se produce gradualmente, y es asumido con más facilidad por las órdenes religiosas que por el clero secular.

\section{LA INCORPORACIÓN A LAS CORRIENTES INTERNACIONALES}

En 1962, la abadía benedictina de Glenstal traba contacto con los promotores de la innovadora arquitectura que se hacía en Italia, Francia y Alemania, y organiza un Congreso de Arquitectura Religiosa. Por otro lado, una publicación religiosa, The Furrow (E1 Surco), informaba regularmente sobre arte religioso y arquitectura eclesial, haciéndose eco de las nuevas tendencias que surgían por doquier. De esta época son los contactos con la revista promovida por el Cardenal

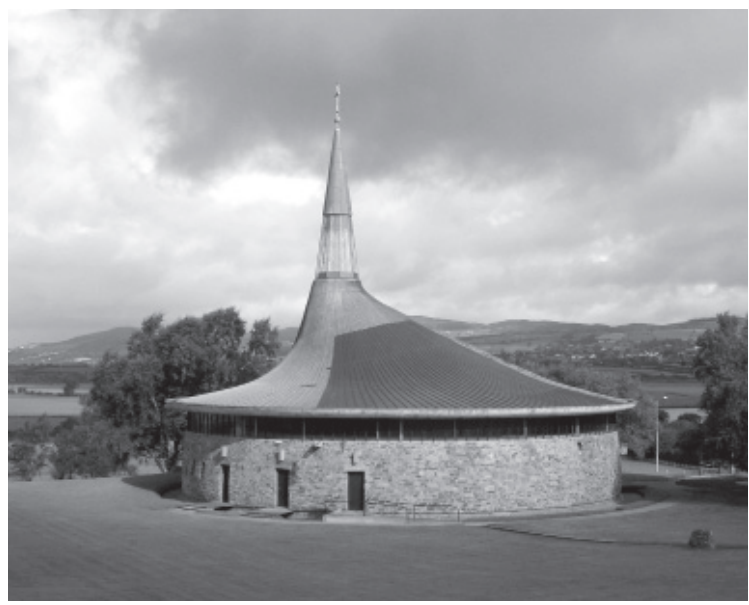

Fig. 10. Liam McCormick, St. Aengus, Burt (1964/65)

Giacomo Lercaro en Bolonia Chiesa e Quartiere.

Respondiendo con prontitud a los cambios litúrgicos derivados del Concilio Vaticano II, surge una nueva generación de iglesias que produce una ruptura radical con las prácticas habituales en las décadas anteriores. Comienzan a explorarse nuevas planimetrías, algunas incluso alejadas de la rigidez del rectángulo, intentando dar respuesta al nuevo enfoque litúrgico posconciliar. Los ejemplos más notables serán la iglesia del Corpus Christi, en Knockanure (Ronald Tallon, 1964) (Fig. 8), de sencilla planta todavía rectangular con macizos muros laterales y un frontal completo de vidrieras, y la iglesia de Santa Teresa en Sion Mills, del arquitecto Patrick Haughey (1963/65) (Fig. 9), que adopta una planta y un lenguaje similares a los de Knockanure, aunque con un exterior más relevante, gracias al majestuoso friso de pizarra sobre la entrada representando la Ultima Cena, obra del escultor Oisin O’Nelly.

Pero el arquitecto más importante de esta generación es Liam McCormick. En Burt, crea la primera obra maestra postconciliar en Irlanda: St. Aengus (1964/65) (Fig. 10). Se trata de una iglesia de planta circular, como las antiguas fortificaciones celtas en las colinas próximas a la misma, y con los asientos dispuestos en tres bandas alrededor del altar. Su enigmática forma, con muros de ruda mampostería y una cubierta de cobre a modo de carpa, junto con su estre- 

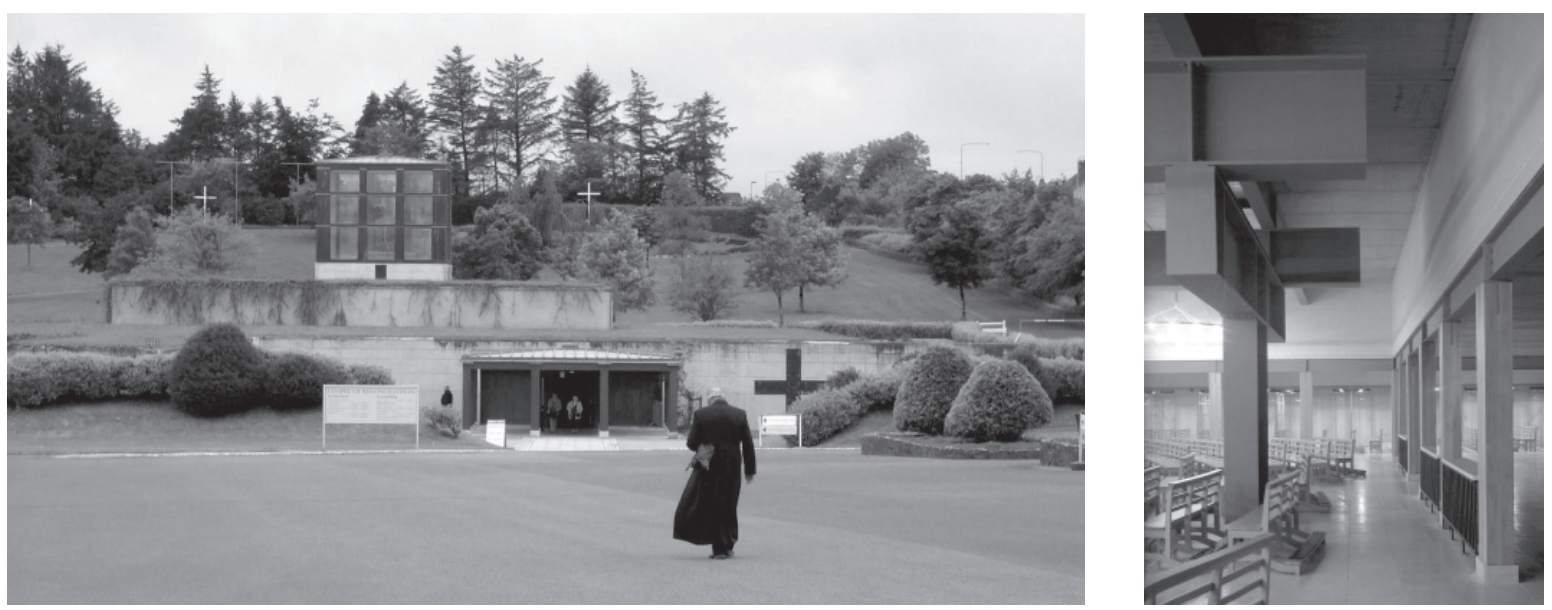

Figs. 11-12. Shane de Blacam y John Meagher, Capilla de la Reconciliación en el Santuario de Nuestra Señora de Knock (1989/90). Exterior e interior

cha vinculación con el entorno, la convierten en una de las iglesias más celebradas de Irlanda. El socio de McCormick, Frank Corr, también experimentará con plantas curvilíneas, como la elíptica de St. Clemens Retreat Chapel, en Belfast (1966/67), y la mucho más imponente Church of the Redeemer en Dundalk (1966/69). Ya en solitario, McCormick continuará creando destacadas iglesias con una amplia variedad de enfoques y una excepcional sensibilidad hacia el entorno, como la iglesia de Creeslough (1970/71), inspirada en Ronchamp, o la de Fossa, cerca de Killarney (1977/79), muestras todas ellas del efectivo mecenazgo hacia los artesanos irlandeses del vidrio policromado, de la forja del metal y de la escultura ${ }^{5}$.

Se podría considerar que el periodo de construcción de iglesias más abundante en la Irlanda del siglo $\mathrm{XX}$ encuentra su punto de inflexión en una obra, hasta cierto punto, emblemática: la Capilla de la Reconciliación en el Santuario de Nuestra Señora de Knock, acaso el lugar de mayor devoción popular para los católicos irlandeses (1989/90) (Figs. 11 y 12). En este santuario mariano, visitado por el papa Juan Pablo II en repetidas ocasiones, Shane de Blacam y John Meagher han logrado una forma sencilla y elegante. Ancestrales pulsiones de honda raigambre céltica $-\mathrm{y}$ por tanto, pagana - recorren los muros de esta obra. Un edificio que es acogido dentro del terreno en última entrega a Eriu, la Madre Tierra, en una vuelta hacia el comienzo de todas las cosas. Todo esto, retomado por el espíritu católico, se transforma en el simbólico descenso a los abismos, la conciencia en ellos de toda falta $\mathrm{y}$, finalmente, la purificación mediante el redescubrimiento de la Luz. La arquitectura se hace eco de todo esto planteando una ascensión hasta un espacio inmaterial creado por los rayos del sol que entran a través del lucernario cúbico, única parte del edificio que emerge del perfil del terreno. Y quizás, por una cierta similitud, nos venga entonces a la memoria la imagen del rayo solar que, en el solsticio de verano, recorre el pasillo central de la imponente tumba celta de Newgrange hasta la cámara sepulcral.

Irlanda es fiel a sus raices. Y la arquitectura lo celebra.

\section{NOTAS}

(1) Valgan como muestra las iglesias presbiterianas de Hillhall (Vincent Craig, 1901) y de Letterkenny (Blackwood y Jury, 1907).

(2) Para el desarrollo de la arquitectura neo-hiberno-románica durante los siglos diecinueve y veinte, puede consultarse el trabajo de Paul Larmour «The Celtic Revival and a Nacional Style of Architecture», tesis doctoral inédita, The Queens University of Belfast, 1977. Para lo referente al «Irish Revivalism» en general, puede verse la obra de Jeanne Sheehy, «The Rediscovery of the Ireland's Past: The Celtic Revival 1830-1930», Londres, 1980.

(3) Edgard Martín, «The New Parish church for Spiddal», The Leader 6:16 (1903), pág. 248-8

(4) Cf. «A Breakaway from Convention», The Irish Builder and Engineer, 21 de noviembre de 1931, pág. 1018.

(5) Otras dos iglesias de planta compleja son la del Espíritu Santo de San Leonardo (Wilfred Cantwell, Ballycullane, 1971) y Nuestra Señora de la Navidad (Richard Turley, Newton, 1975). 